\title{
Applied Anatomic Study of Testicular Veins in Adult Cadavers and in Human Fetuses
}

\author{
Luciano A. Favorito, Waldemar S. Costa, Francisco J.B. Sampaio
}

Urogenital Research Unit, State University of Rio de Janeiro, Rio de Janeiro, Brazil

\begin{abstract}
Objectives: Analyze the anatomic variations of the testicular veins in human cadavers and fetuses.

Materials and Methods: One hundred male adult cadavers and 24 fetuses were studied. Four anatomic aspects were considered: 1) Number of testicular veins, 2) The local of vein termination, 3) Type and number of collaterals present and 4) Testicular vein termination angle.

Results: Cadavers - Right side - One testicular vein occurred in $85 \%$ and 2 veins in $5 \%$ of the cases. There were communicating veins with the colon in $21 \%$ of the cases. Left side - One testicular vein occurred in $82 \%$, two veins in $15 \%$, three veins in $2 \%$ and four veins in $1 \%$ of the cases. There were communicating veins with the colon in $31 \%$ of the cases. Fetuses - Right side -One testicular vein occurred in all cases. This vein drained to the vena cava in $83.3 \%$ of the cases, to the junction of the vena cava with the renal vein in $12.5 \%$ and to the renal vein in $4.2 \%$. There were communicating veins with the colon in $25 \%$ of the cases. Left side - One testicular vein occurred in $66.6 \%$ of the cases, and 2 veins in occurred $33.3 \%$. Communicating veins with the colon were found in $41.6 \%$ of the cases.

Conclusion: The testicular vein presents numeric variations and also variations in its local of termination. In approximately $30 \%$ of the cases, there are collaterals that communicate the testicular vein with retroperitoneal veins. These anatomic findings can help understanding the origin of varicocele and its recurrence after surgical interventions.
\end{abstract}

Key words: testis; spermatic cord; veins; varicocele; anatomy

Int Braz J Urol. 2007; 33: 176-80

\section{INTRODUCTION}

Varicocele consists in the dilation of the pampiniform plexus veins, mainly on the left side. It is a frequent pathology that occurs in approximately $15 \%$ of male population, including children $(1,2)$. Varicocele can be an important cause of male infertility, and approximately $41 \%$ of infertile male patients present varicocele (3).

Testicular venous drainage is done through the pampiniform plexus, which in the region of the internal inguinal ring gives origin to the testicular vein.
The left testicular vein discharges in the left renal vein in a straight angle, whereas the right testicular vein discharges directly in the inferior vena cava in an oblique angle (4). The testicular veins present valves in all its extension. In the region of the fourth lumbar vertebra the testicular veins divided into two trunks, one lateral and one medial $(4,5)$. The lateral trunk is anastomosed with retroperitoneal veins, mainly colonic and renal capsular veins, and the medial trunk is anastomosed with ureteral veins. Anastomoses between the two venous trunks are also found $(4,5)$. 
Studies on the anatomic distribution of the testicular veins performed in cadavers are scarce $(2,4)$. These studies were done in fixed cadavers through the dissection of the retroperitoneum with identification of the course of the gonadal vessels. There are no studies in the indexed literature on the anatomy of the testicular veins performed in human fetuses.

The objective of this work is to present an analysis of the anatomical variations of number, local of drainage and collaterals of the testicular veins, as well as of its distribution in cadavers and in human fetuses.

\section{MATERIALS AND METHODS}

From December 1998 to July 2006, 100 formalin-fixed cadavers and 24 fresh male fetuses were studied. The cadavers were aged between 25 and 75 years and did not present previous abdominal surgery. Identification of testicular veins was performed through simple dissection. Four anatomic findings were considered: 1) Number of testicular veins and the local of its division, 2) The local of the vein termination (inferior vena cava, renal vein or angle between the renal vein and the inferior vena cava), 3) The type and the number of collaterals (supra-renal, lumbar, accessory testicular) and 4) The angle of testicular vein termination.

The fetuses studied were in excellent state of conservation and ranged in age between 20 and 35 weeks post-conception (WPC), calculated through the measurement of the largest feet (6-9). To study the testicular veins in fetuses, a polyester microvascular resin was injected through the intracardiac inferior vena cava, after a thoracotomy, aiming to facilitate the identification and dissection of the testicular veins, as described in previous papers (10). The same anatomic aspects analyzed for the adults were considered for the fetuses.

\section{RESULTS}

\section{Adult Cadavers}

Right testicular vein - Of the 100 cases, we observed the presence of 1 testicular vein in $85 \%$ and of 2 veins in $15 \%$, totaling 115 testicular veins. The local of drainage of the testicular vein when it has only one trunk was the inferior vein cava in 99 cases and in 1 case the sole testicular vein drained to the right renal vein (Figure-1). Among the 15 cases presenting 2 testicular veins, in 7 cases the testicular vein ended in the angle between the renal vein and the inferior vena cava. In $98 \%$ of the cases, the testicular vein drained in the vena cava in an acute angle, and in 1 case, the angle was straight. In $21 \%$ of the cases, we observed collateral veins communicating with the colon, which derived from the lateral division of the gonadal vein (Figure-2).

Left testicular vein - Of the 100 cases, we observed the presence of 1 testicular vein in $82 \%$ of the cases, 2 veins in $15 \%$ of the cases, 3 veins in $2 \%$

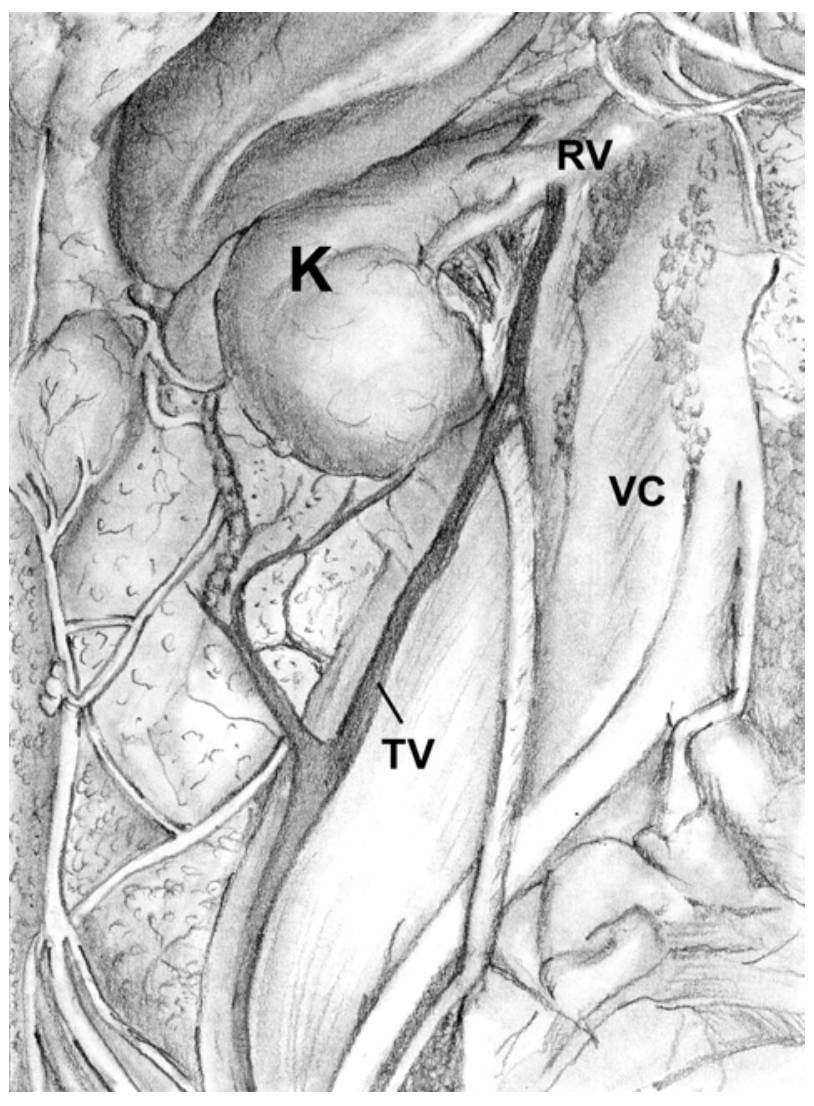

Figure 1 - Schematic drawing highlights a cadaver where the right testicular vein $(T V)$ discharges in the right renal vein $(R V)$. $V C=$ inferior vena cava $;=$ kidney. 


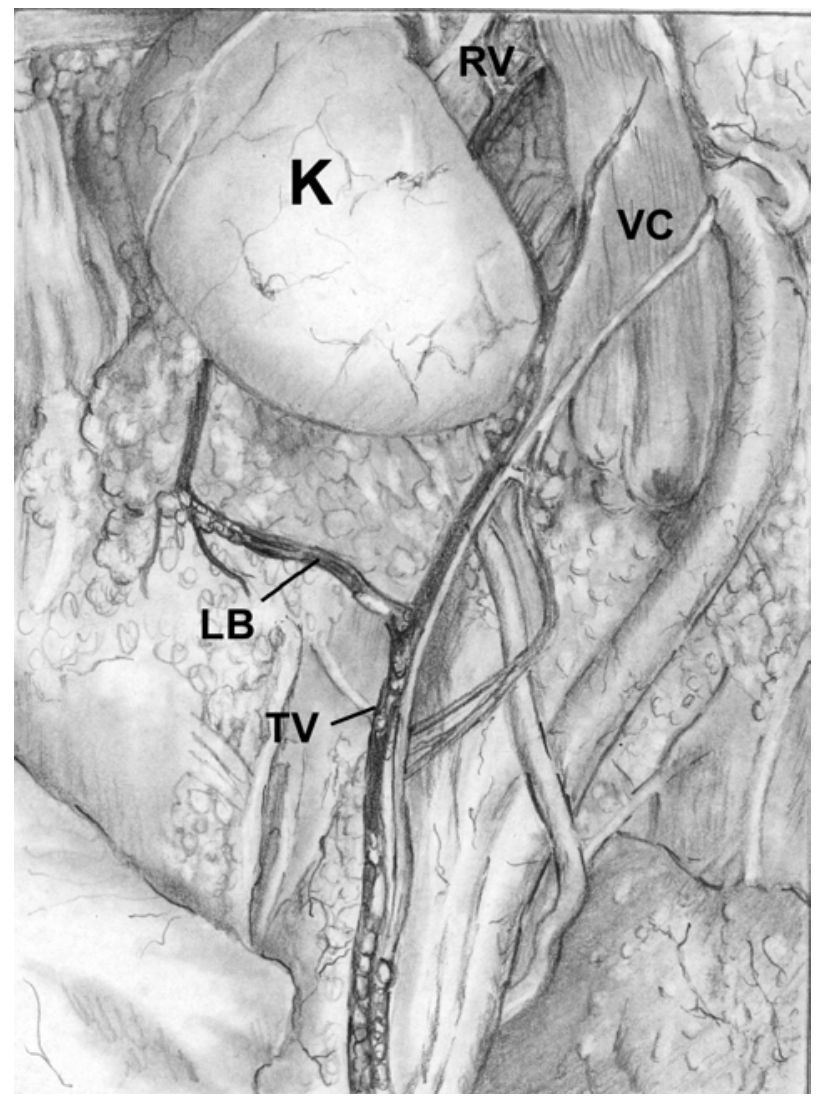

Figure 2 - Schematic drawing highlights the division of the testicular vein, originating a lateral branch $(L B) . V C=$ inferior vena cava, $R V=$ right renal vein; $K=$ kidney.

of the cases and 4 veins in $1 \%$ of the cases, totaling 122 testicular veins in the left side. The local of drainage of the left side testicular veins was the renal vein in all cases (Figure-3), independently of the number of testicular veins. The angle of drainage of the left testicular vein in the renal vein was straight in $95 \%$ of the cases. We observed the presence of veins communicating with the colon, derived from the lateral division of the gonadal vein, in $31 \%$ of the cases.

\section{Fetuses}

Right testicular vein - Of the 24 cases, we observed the presence of only 1 testicular vein in all cases. The local of drainage of the testicular vein was in the inferior vena cava in $83.3 \%$ of the cases, in the junction of the renal vein with the inferior vena cava in $12.5 \%$, and in the renal vein in $4.2 \%$ of the cases.
In $95.8 \%$ of the cases, the testicular vein drained in the vena cava with an acute angle, and in 1 case, the angle was straight. The presence of communicating veins with the colon, derived from the lateral division of the gonadal vein, was found in 6 cases $(25 \%)$.

Left testicular vein - Of the 24 cases, we observed the presence of 1 testicular vein in $66.6 \%$ of the cases and 2 veins in $33.3 \%$ of the cases, totaling 32 left testicular veins. In all cases, the local of drainage of the left testicular veins was the renal vein. The left testicular vein drained in the renal vein with a straight angle in $93.75 \%$ of the cases, and in 2 cases $(6.25 \%)$, the angle was acute. The presence of communicating veins with the colon, derived from the lateral division of the gonadal vein, was found in 10 of the 24 fetuses $(41.6 \%)$.

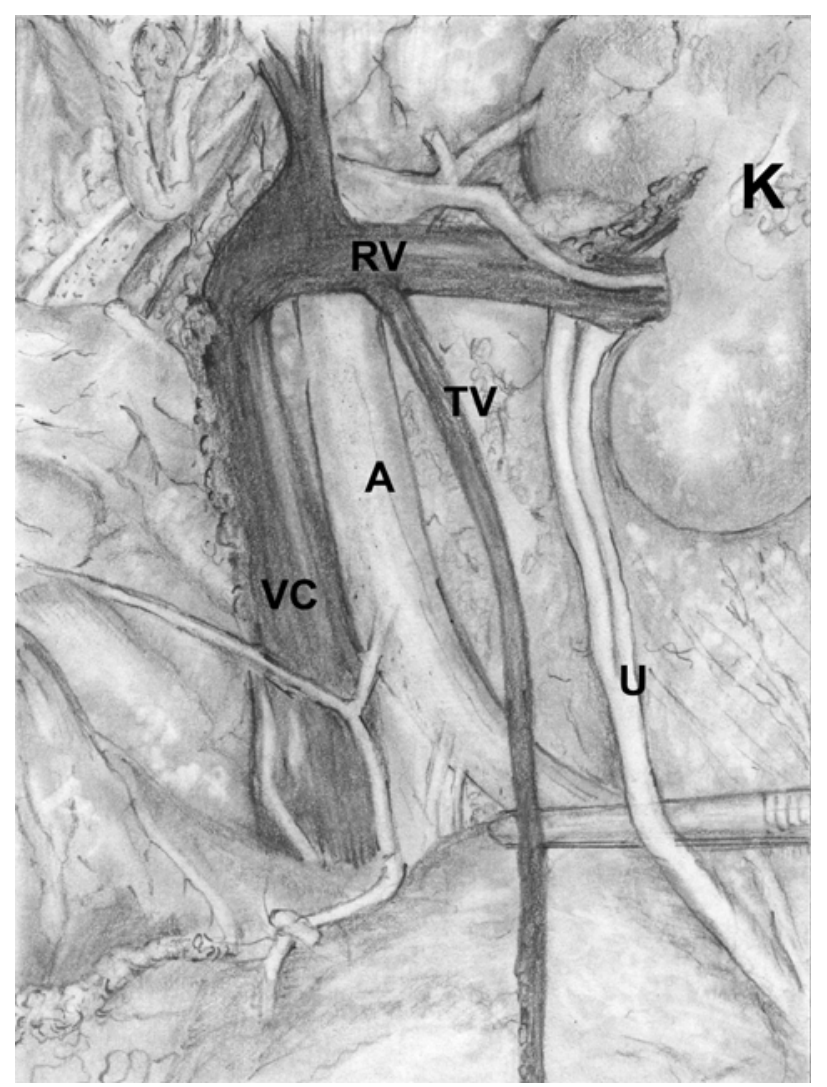

Figure 3-Schematic drawing highlights a cadaver where there is no division of the left testicular vein (TV), which drains in a straight angle at the left renal vein $(R V) . V C=$ inferior vena cava, $A=$ aorta, $U=$ ureter $;=$ kidney. 


\section{COMMENTS}

Anatomic variations of the testicular vein are frequent, especially concerning the number of left side gonadal veins and the angle of termination of these veins (4). These variations can be explained by the persistence of primary venous systems that during the embryological period originate the inferior vena cava $(1,11)$. The left gonadal vein develops between the 5 th and the 7th weeks after conception, being derived from the distal or post-renal portion of the sub-cardinal vein (12). In our sample, we have observed the presence of variations in the number of testicular veins of the right side in $15 \%$ of the cases in adult cadavers. In the left side, we found the presence of multiple veins in $18 \%$ of the cases in adult cadavers and in $33 \%$ of the case in fetuses, corroborating the high incidence of numeric variation in the gonadal veins.

Anatomic variations of the local of drainage of the testicular veins were found mainly at the right side. All left testicular veins (either single of multiple) drained to the renal vein, while the right testicular vein drained to the inferior vena cava in more than $83 \%$ of the cases.

The treatment of varicocele can be performed through various methods. This can be accomplished by open surgery, videolaparoscopic surgery (13) or sclerotherapy (14). The objective of the treatment is the obliteration of the veins that drain the testicle, while preserving the vas deferens and the testicular artery (15). However, some studies report that the ligature of the testicular artery together with the testicular vein decreases the recurrence index after varicocele surgery, since there are little veins close to the adventitia of the artery that can become varicose after the exclusion of the main testicular vein, causing the recurrence of the varicocele (16).

During performance of sclerotherapy, a contrast medium is injected into the testicular veins, allowing the visualization of the valves and the number and the course of the veins (1). Previous studies have made evident that in approximately $74 \%$ of the cases, the patients could present insufficiency in the valvar mechanisms of the gonadal veins (1). In the present study, an analysis of the presence of valves in the testicular vein was not accomplished.
In the past, the presence of collateral branches of testicular veins was considered as anomaly, nevertheless, a previous study with adults and neonates have found approximately $74 \%$ of gonadal veins collaterals communicating with the colon (4). In our sample, we found collaterals to the colon in $31 \%$ of the adult cadavers and in $41 \%$ of the fetuses.

The incidence of recurrence after surgical cure of varicocele varies from 0.6 to $45 \%$ (17), being the recurrence most common after surgeries performed in pediatric patients (17). One of the factors that seem to be involved in the recurrence after surgery of varicocele is the anatomical distribution of the testicular veins in the retroperitoneum (4). The presence of collateral veins communicating the testicular vein with veins of the colon and with collateral veins at the opposite side, could explain the compromise of spermatogenesis in cases of unilateral varicocele, as well as the recurrence of varicocele after surgery (4). The type of surgical technique could also favor recurrence. Retroperitoneal ligature are the surgical procedure that course with the highest rates of recurrence, between 10 and 15\% (12). Microsurgical subinguinal ligature is today the technique of choice for varicocele surgery, since this technique is performed in a region that is closer to the testicle, decreasing the chance of collaterals reactivation through retroperitoneal anastomoses.

\section{CONCLUSIONS}

Variations in the number and in the local of termination are frequent. In approximately $30 \%$ of the cases, there are collaterals that communicate testicular veins with retroperitoneal veins. These anatomical findings can help in understanding the origin of varicocele and its recurrence after surgical interventions.

\section{ACKNOWLEDGMENT}

Research supported by FAPERJ (Rio de Janeiro Foundation for Research Support) and CNPQ (National Council for Scientific and Technological Development), Brazil. 


\section{CONFLICT OF INTEREST}

None declared.

\section{REFERENCES}

1. Braedel HU, Steffens J, Ziegler M, Polsky MS, Platt ML: A possible ontogenic etiology for idiopathic left varicocele. J Urol. 1994; 151: 62-6.

2. Akbay E, Cayan S, Doruk E, Duce MN, Bozlu M: The prevalence of varicocele and varicocele-related testicular atrophy in Turkish children and adolescents. BJU Int. 2000; 86: 490-3.

3. Beck EM, Schlegel PN, Goldstein M: Intraoperative varicocele anatomy: a macroscopic and microscopic study. J Urol. 1992; 148: 1190-4.

4. Wishahi MM: Detailed anatomy of the internal spermatic vein and the ovarian vein. Human cadaver study and operative spermatic venography: clinical aspects. J Urol. 1991; 145: 780-4.

5. Sofikitis N, Dritsas K, Miyagawa I, Koutselinis A: Anatomical characteristics of the left testicular venous system in man. Arch Androl. 1993; 30: 79-85.

6. Hern WM: Correlation of fetal age and measurements between 10 and 26 weeks of gestation. Obstet Gynecol. 1984; 63:26-32.

7. Mercer BM, Sklar S, Shariatmadar A, Gillieson MS, D'Alton ME: Fetal foot length as a predictor of gestational age. Am J Obstet Gynecol. 1987; 156: 350-5.

8. Platt LD, Medearis AL, DeVore GR, Horenstein JM, Carlson DE, Brar HS: Fetal foot length: relationship to menstrual age and fetal measurements in the second trimester. Obstet Gynecol. 1988; 71: 526-31.

9. Streeter GL: Weight, sitting. height, head size, foot length, and. menstrual age of the human embryo. Contrib Embryol Carnegie Inst. 1920; 11:143-70.

10. Sampaio FJ, Favorito LA, Freitas MA, Damiao R, Gouveia E: Arterial supply of the human fetal testis during its migration. J Urol. 1999; 161: 1603-5.

11. Itoh M, Moriyama H, Tokunaga Y, Miyamoto K, Nagata W, Satriotomo I, et al.: Embryological consideration of drainage of the left testicular vein into the ipsilateral renal vein: analysis of cases of a double inferior vena cava. Int J Androl. 2001; 24: 142-52.

12. Forte F, Latini M, Foti N, Sorrenti S, De Antoni E, Virgili $\mathrm{G}$, et al.: Bahren types III and IVa testicular vein anomalies as a reason for failure in left idiopathic varicocele retrograde sclerotherapy. Ontogenic discussion and clinical implications. Surg Radiol Anat. 2001; 23: 42731.

13. Nagler HM, Luntz RK, Martinis FG: Varicocele. In Lipshultz LI, Howars SS (eds.), Infertility in the male. Third edition. St.Louis, Mosbi Year Book. 1997.

14. Tauber R, Johnsen N: Antegrade scrotal sclerotherapy for the treatment of varicocele: technique and late results. J Urol. 1994; 151: 386-90.

15. Pryor JL, Howards SS: Varicocele. Urol Clin North Am. 1987; 14: 499-513.

16. Matsuda T, Horii Y, Yoshida O: Should the testicular artery be preserved at varicocelectomy? J Urol. 1993; 149: 1357-60.

17. Goldstein M: Complications and results of varicocelectomy. In: Surgery of male infertility. Phyladelphia, WB Saunders Company. 1995; pp. 194-6.

\author{
Correspondence address: \\ Dr. Luciano A. Favorito \\ Urogenital Research Unit - UERJ \\ Av. 28 de Setembro, 87 - fundos - FCM - terreo \\ 20551-030, Rio de Janeiro, RJ, Brazil \\ Fax: + 5521 2587-6121 \\ E-mail: lufavorito@yahoo.com.br
}

